\title{
IN MEMORIAM DR. CAROL S. KELLY
}

\section{Bettina Terp and Varda Mann-Feder}

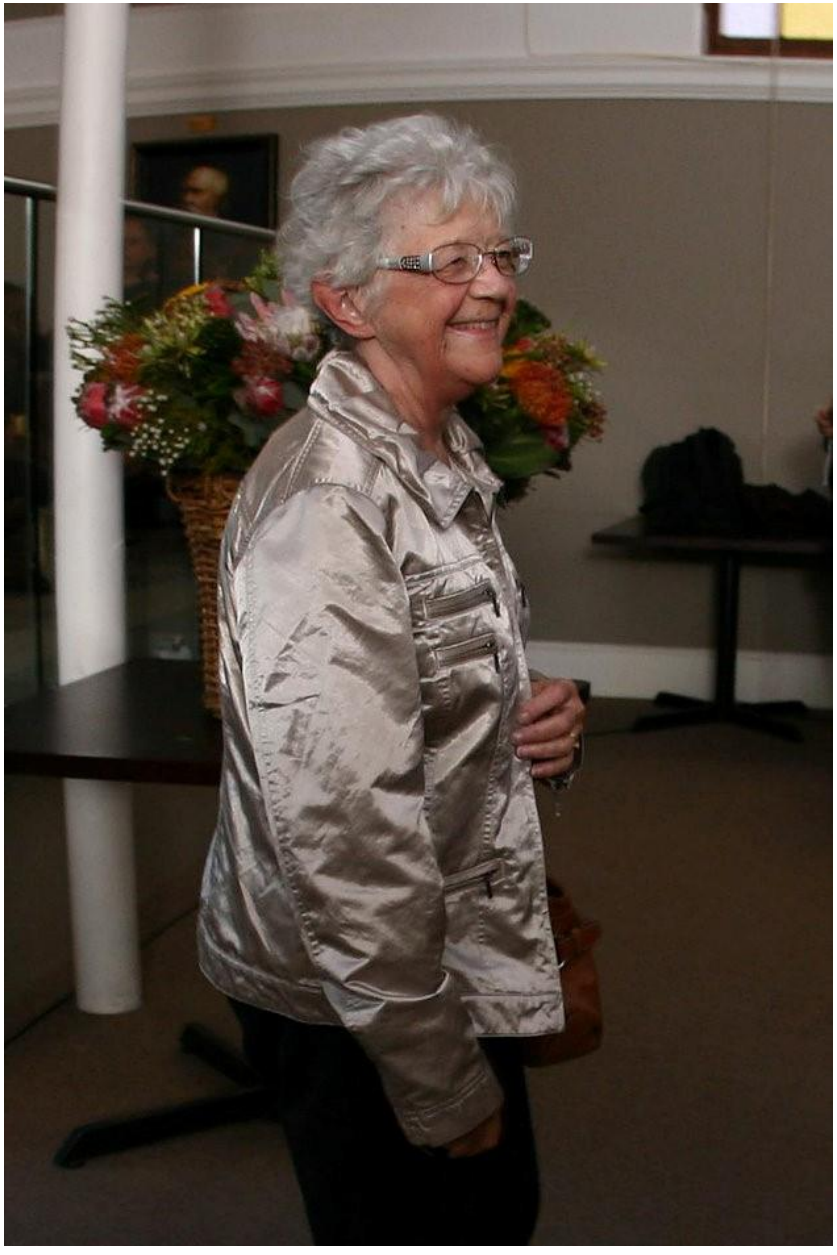

Dr. Carol S. Kelly was born May 15, 1939 in Marion, Ohio, and passed away on Friday, February 10, 2017 at Thousand Oaks, California.

Dr. Carol S. Kelly began her teaching career in 1969 at California State University, Northridge, in the College of Human Development. Carol provided key leadership in developing and implementing the interdisciplinary program in child development, and in working across and beyond campus to strengthen the program, which later became the Department of Child and Adolescent Development. Having established a legacy through her teaching, she continued to mentor students and alumni as a professor emeritus after retiring in 2007.

Carol was among the original founders of the National Organization for Child Care Worker Associations (NOCCWA), which was the first national CYC association in the United States and the precursor of ACYCP, the Association for Child and Youth Care Practice. Carol served overseas 
as a senior consultant for the United Nations International Year of the Family. In recent years, she was an active member of the FICE board, an ardent leader of the Martha Mattingly Scholarship committee, and a contributing member of ACYCP. Her retirement from the university did not in any way diminish her energy or her contributions. Carol believed in professionalization, certification, accreditation, and international collaboration. She was deeply committed to generativity and the cultivation of emerging leaders. The Child and Adolescent Development Alumni Chapter of California State University recently referred to her as a "transformative figure ... who established a legacy through her teaching ... and continued to mentor students and alumni as a professor emeritus".

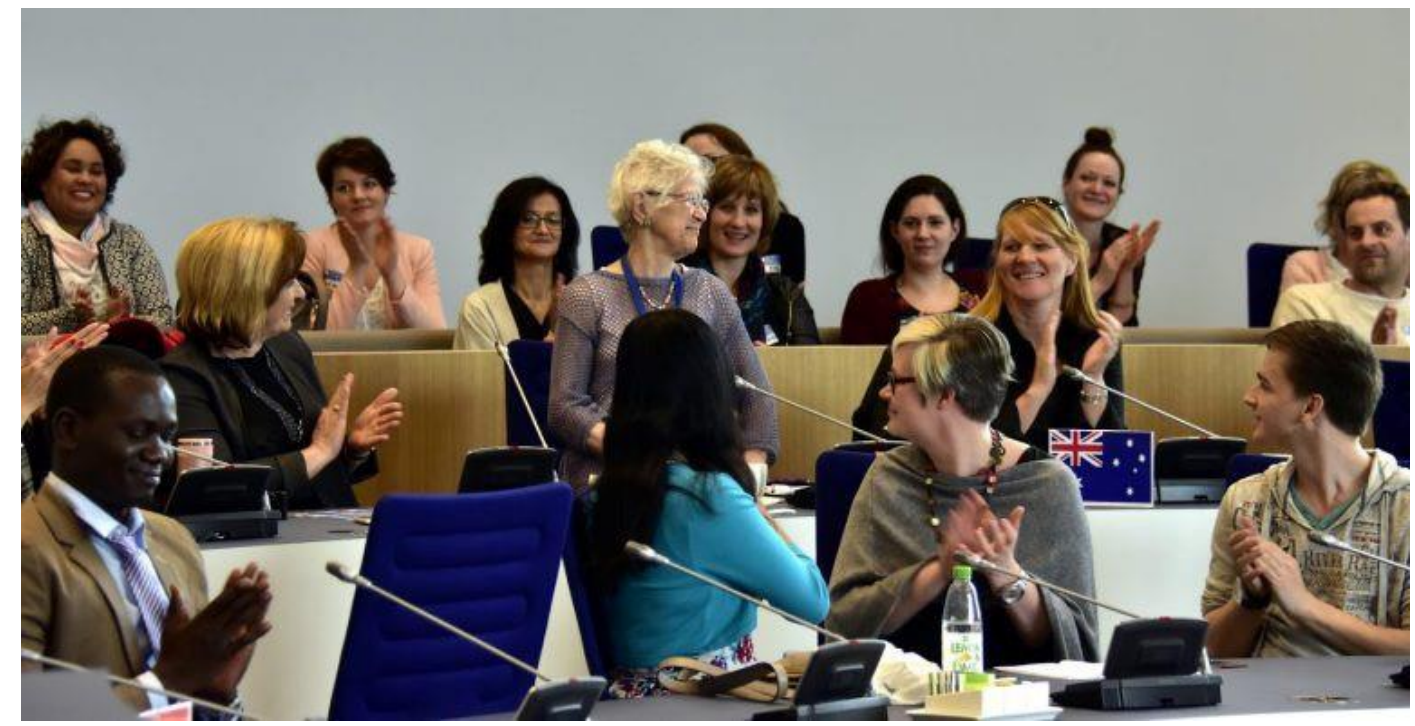

Carol was appointed FICE USA representative at the 1994 FICE Congress in Milwaukee.

In 1994, at the FICE Congress in Milwaukee, Carol was announced as representative for FICE USA. She worked tirelessly and diplomatically to maintain the presence of FICE USA in the FICE International community.

Even at the beginning of her dedication to FICE International, Carol was tiny and had white hair. She could have been mistaken for a favourite grandmother as she smiled fondly at everyone. However, her physical energy and razor-sharp mind belied her years. She came regularly to FICE meetings from the West Coast of America and still had the stamina to participate fully in the whole programme of activities.

Professionally she was deeply committed to keeping alive professional links across North America and the rest of the FICE family, because she realised the importance of networking and learning from each other. She would often be the first to reach out to new members when they came to meetings, and always gave her undivided attention when others were speaking. Networking is one of the main strengths of FICE and Carol excelled at it. 
Carol was the recipient of numerous awards throughout her career, but one of her proudest moments came when she was awarded the 2016 Lifetime Achievement Award by ACYCP. This event was part of the 33rd FICE Congress in Vienna, Austria in August 2016.

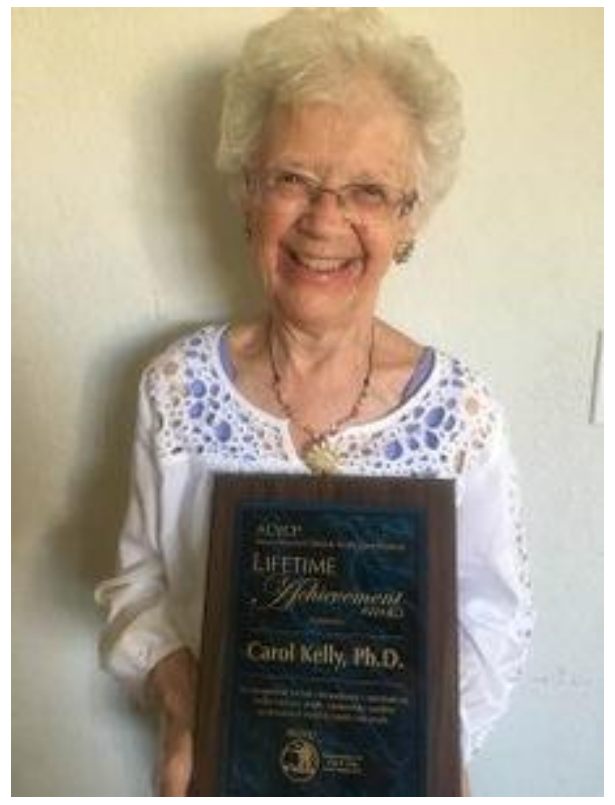

Receiving the ACYCP Lifetime Achievement Award.

In a recent newsletter, the nominator was quoted as saying that Carol "was an extraordinary force in CYC for over 50 years, in which she unselfishly dedicated her life to making the world a better place for children. ... Her impassioned efforts as a change agent has led to the development of ground breaking policies both nationally and internationally ... her legacy extends from Russia to Finland to Africa and the USA". Carol Kelly achieved much in her lifetime and her efforts will have a profound impact on CYC for years to come.

Carol was a person who had the capacity to touch and influence people, especially young ones. We thought it appropriate to quote part of a very emotional tribute written by one of FICE's youngest delegates, Simon Peter from Kenya:

As the curtain falls for the Icon Carol, Her [passing] has caught everyone's attention, It's hard to believe ... She galvanized the hopes and aspirations of many members, inspired the sense of responsibility, she was such a brilliant analyst capable of thinking tactfully and practically. I had the privilege of spending time next to her during the many conferences and I benefited from her voice of reason and moderation. Carol struck consistently by how much her strength at the conferences affected my strength back in Kenya. She gave me hopes of how many years I have ahead for the work with children at risk. I kept asking myself ... how did a person so of age simultaneously cross seas and oceans to contribute to the policies and practices in pursuit of a simple dream, "the rights of children at 
International Journal of Child, Youth and Family Studies (2018) 9(1): 5-8

risk?"... We appreciate the honour of having known Carol as we admit that the loss is terrible for FICE, family, and friends.

This is just one example of many moving tributes to Carol Kelly that are posted on FICE's website: https://www.ficeinter.net/single-post/2017/05/19/In-Memoriam-Dr-Carol-S-Kelly.

When referring to FICE's work for children and young people, or to particularly successful projects, like "Isibindi", or to groundbreaking effects of international cooperation, Carol had her own favourite phrase for paying the highest possible compliment, saying, "It's priceless beyond words."

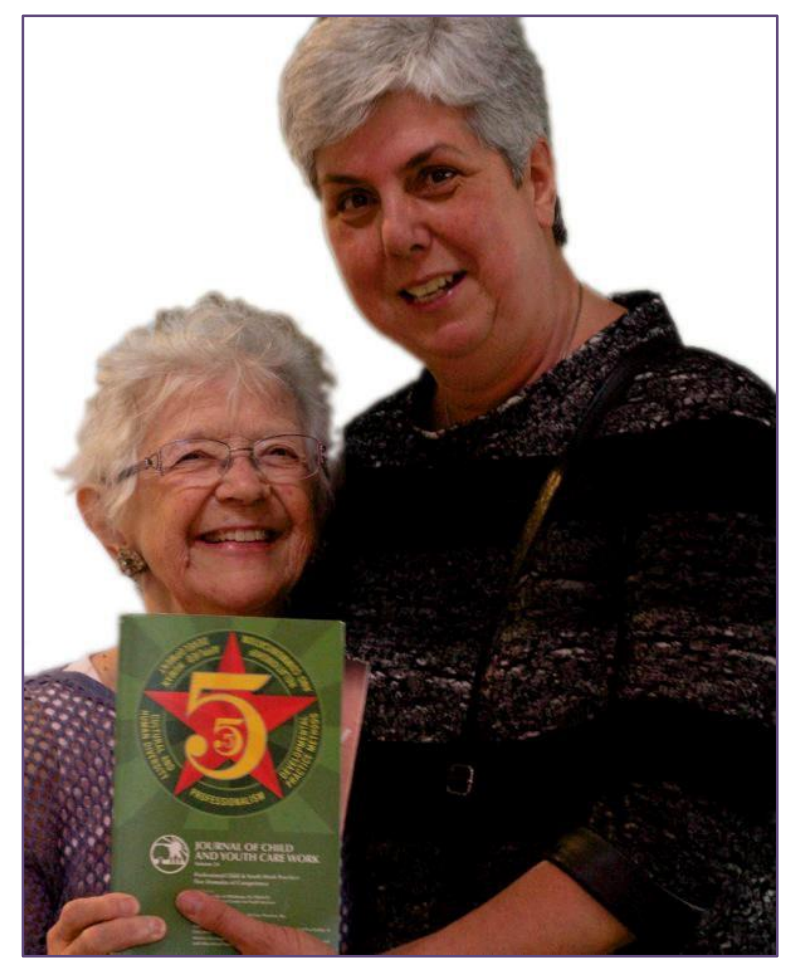

Carol with Gitta Griffioen, FICE Netherlands.

On a personal level, Carol was small in stature but mighty of spirit. Her greatest gift was her ability to connect with people. Those of us who had the pleasure of interacting with her experienced her talent for communication and her love of conversation. Carol had an encyclopaedic knowledge of our field and served as a great resource. She always had so much to share. Carol was a devoted grandmother who frequently expressed her love for her family, her colleagues, her students, her neighbours, and for the field of Child and Youth Care.

For us in the FICE family, and for the whole Child and Youth Care Community, the privilege of having worked, talked, and laughed with Carol was definitely "priceless beyond words". We have lost a tiny giant human, a highly professional colleague, and a dear friend. 